says Kovacs Burns. "There are lots of international charters put out by the World Health Organization and other groups that are respected without being legislated, so it's possible. But so long as we're operating in silos, there's no ownership in these policies."

It's all too easy for nonbinding policy to become diluted in the murky waters of federal and provincial responsibility, says Binder. "I don't think you'll ever see something like that implemented on a national level because the federal government will say it's the jurisdiction of the provinces, and I doubt the provinces will want to take on the cost of enforcing this thing."

Past recommendations that the federal government enact a national patient charter have "died a natural death" for that very reason, says Philp, citing failed federal private members' bills tabled in the early-2000s.

But more important than the charter itself is the opportunity it will provide for patients to join the discussion on health care transformation, she says. "It's about time we had a conversation across the country about the future of health care, and at least this is sparking discussion about what's best for patients, first and foremost."

To date, conversations surrounding patient charters have been fairly onesided, says Frances Jewell, executive director of the Mental Health Rights Coalition of Hamilton, an Ontariobased advocacy group. "Patient-centred care is a sexy buzzword right now, and people are eager to jump on board. But who's determining what the patients' needs are? I'm regularly contacted last minute when a group wants to push some charter or patient-centred policy through, and out of the blue they want me to rubber stamp this and throw together a consumer panel on that, because they're on a deadline. I don't appreciate well-meaning organizations speaking on my behalf."

Canada's checkerboard experience with patient charters means it's anyone's guess if a national charter will be more buzz or bite, she says. "It's been easy to direct services for people and say we're doing patient-centred care. That's no longer acceptable." - Lauren Vogel, CMAJ

DOI:10.1503/cmaj.109-3340

Second in a three-part series on patient charters

Part I: Patients charters: the provincial experience (www.cmaj.ca/cgi/doi /10.1503/cmaj.109-3339)

Part III: Patient charters: the international experience (www.cmaj.ca/cgi/doi /10.1503/cmaj.109-3342)

\title{
Nation's physicians urge re-opening of Canada Health Act
}

Previously published at www.cmaj.ca

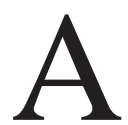
n overhaul of the Canada Health Act, detailed financial information about the long-term costs of health care and re-examination of the role and responsibilities of physicians in managing health care are among elements identified as integral to transformation of the health care system during the 143rd annual general meeting of the Canadian Medical Association.

The list included a call for the inclusion of "sustainability" as a new core and protected principle of medicare, as well as a "re-interpretation" of the Canada Health Act's five principles: universality, accessibility, portability, comprehensiveness and public administration.

The call for concrete information about the costs of health care came from Auditor General of Canada Sheila Fraser, who contended Canada should not make decisions about health care reform without long-term cost projections on the order of 25 or more years.

The role of doctors in the system, meanwhile, prompted the gathering's most heated debate, with some physi- cians decrying the marginalization of physicians in the management of the system and others arguing that doctors should eschew greater involvement in medicare on the grounds that the system's collapse is inevitable. CMA was charged with establishing a working group to investigate the issue.

Delegates adopted a pair of motions aimed at overhauling the Canada Health Act (CHA). One supported recognition of a sixth principle, "sustainability," that would define "standards of health human resources, infrastructure, clinical

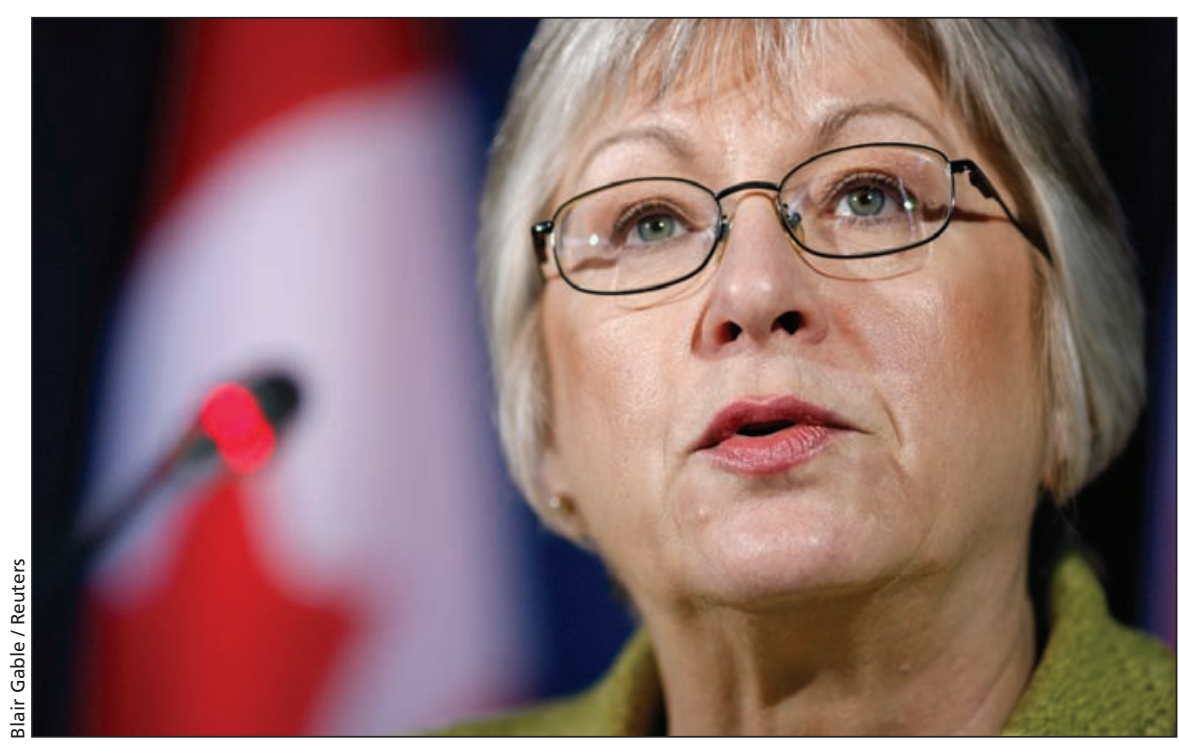

Canada should not make decisions about health care reform without long-term cost projections on the order of 25 or more years, says Auditor General of Canada Sheila Fraser. 
outcomes and fiscal capacity." The other called on the federal government "to reinterpret the principles of the Canada Health Act in light of the evolution in the delivery of health care services."

Several delegates noted that including sustainability as a CHA principle would be fraught with difficulties, as it may be defined differently by different groups and could undermine federal government enforcement of the act's other principles. But as other delegates noted, the federal government is not enforcing those principles, so the risk may be moot.

New CMA President Dr. Jeff Turnbull sponsored the motion and says that "the establishment and the implementation" of the principles should be scrutinized to see if they are applicable to health care as it's now delivered. "In addition to that, we should see if there's any new principle that we have to consider, such as patient-centredness," he adds. "Quite frankly, I would also consider whether equity should be a principle onto its own right."

Motion co-sponsor Dr. John Tracey, a Brampton, Ontario, family physician and a member of the CMA board of directors, said re-examination of the act's principles should also include an assessment of the "concept of medical necessity."

Several provinces have been forced by rising health care costs to assess what medical services are medically necessary and covered by medicare.

But Fraser argued that such decisionmaking shouldn't be made in an information vacuum. She said that governments cannot ascertain if they have resources to meet public health needs without making sound, long-term financial projections. "Canadians and the government need to know the challenges ahead and how policy choices will affect the financial burden on present and future generations. And fiscal projections that look only a few years down the road won't give them what they need," Fraser said.

She also argued that future federal cash transfers to the provinces for health care should include concrete reporting requirements as current "unconditional" transfers offer no guarantee of accountability. - Wayne Kondro, CMAJ

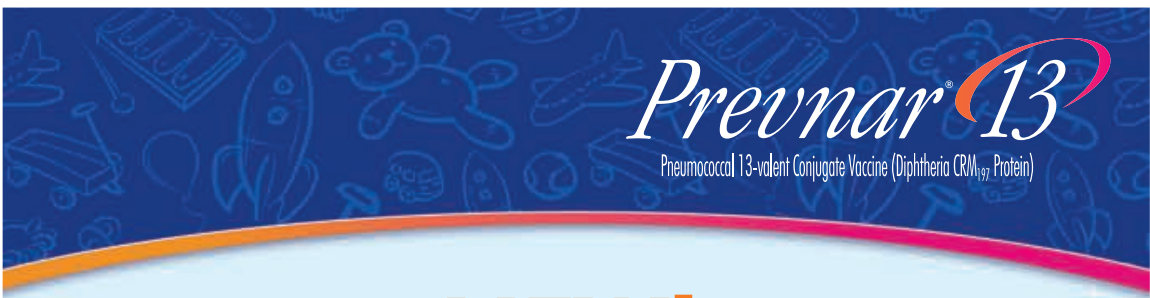
NEW!

\section{PREVNAR' 13 NOW AVALABLE}

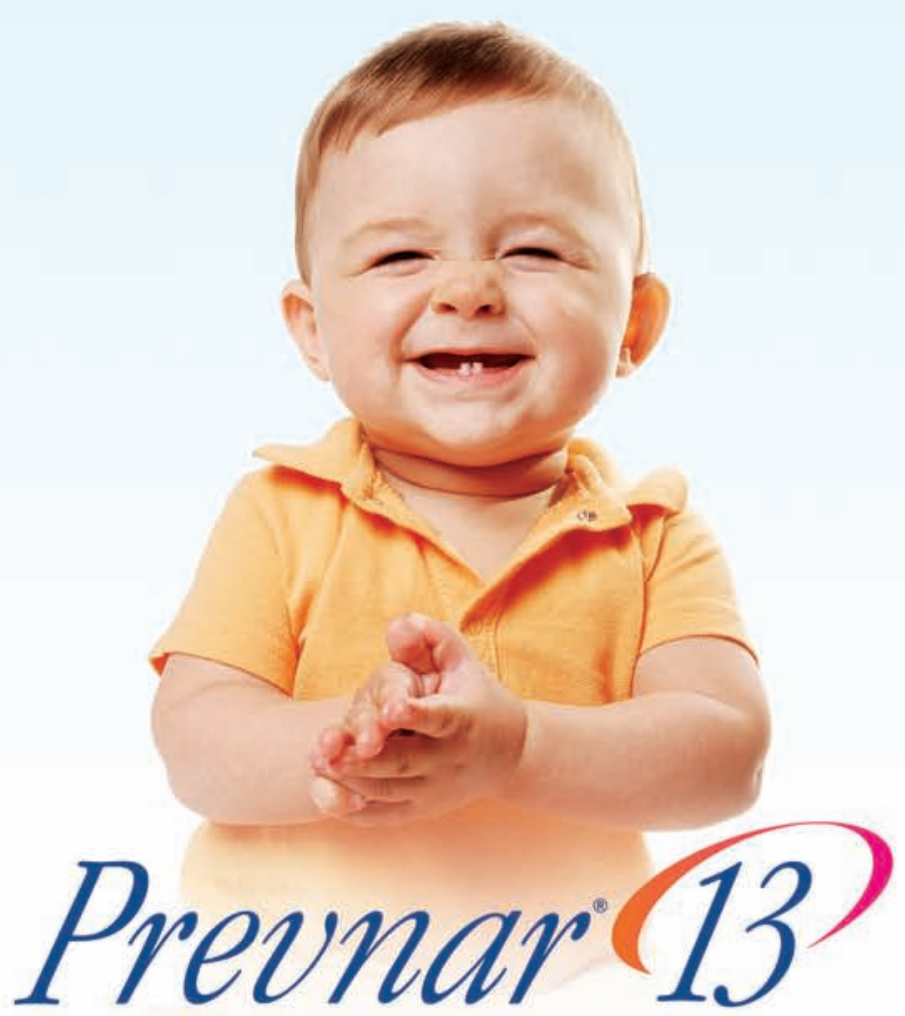

Prevnar 13 is indicated for the active immunization against Streptococcus pneumoniae serotypes $1,3,4,5,6 \mathrm{~A}, 6 \mathrm{~B}, 7 \mathrm{~F}, 9 \mathrm{~V}, 14,18 \mathrm{C}, 19 \mathrm{~A}, 19 \mathrm{~F}$ and $23 \mathrm{~F}$ causing invasive pneumococcal disease, including:

- Sepsis, meningitis, bacteraemic pneumonia, pleural empyema and bacteraemia

- Indicated for use in infants and children from 6 weeks through 5 years of age

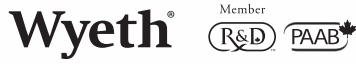

